\begin{tabular}{|c|l|}
\hline Title & Highly strong and conductive carbon nanotube/cellulose composite paper \\
\hline Author(s) & Imai, Masanori; A kiyama, Kousuke; Tanaka, Tomo; Sano, Eiichi \\
\hline Citation & $\begin{array}{l}\text { Composites Science and Technology, 70(10), 1564-1570 } \\
\text { https://doi.org/10.1016/.Compscitech.2010.05.023 }\end{array}$ \\
\hline Issue Date & 2010-09-30 \\
\hline Doc URL & http://hdl.handle.net/2115/43921 \\
\hline Type & article (author version) \\
\hline File Information & CST 70-10_15641570.pdf \\
\hline
\end{tabular}

Instructions for use 


\title{
Highly strong and conductive carbon nanotube/cellulose composite paper
}

\author{
Masanori Imai ${ }^{\mathrm{a}}$, Kousuke Akiyama $^{\mathrm{a}}$, Tomo Tanaka ${ }^{\mathrm{b}}$, Eiichi Sano ${ }^{\mathrm{b}}$ \\ aTokushu Paper Co. Ltd. \\ ${ }^{\mathrm{b}}$ Research Center for Integrated Quantum Electronics, Hokkaido University
}

\begin{abstract}
Carbon nanotube (CNT)/cellulose composite materials were fabricated in a paper making process optimized for a CNT network to form on the cellulose fibers. The measured electric conductivity was from $0.05-671 \mathrm{~S} / \mathrm{m}$ for $0.5-16.7-w t \%$ CNT content, higher than that for other polymer composites. The real permittivities were the highest in the microwave region. The unique CNT network structure is thought to be the reason for these high conductivity and permittivity values. Compared to other carbon materials, our carbon CNT/cellulose composite material had improved parameters without decreased mechanical strength. The near-field electromagnetic shielding effectiveness (EMI SE) measured by a microstrip line method depended on the sheet conductivity and qualitatively matched the results of electromagnetic field simulations using a finite-difference time-domain simulator. A high near-field EMI SE of 50-dB was achieved in the 5-10 GHz frequency region with $4.8-\mathrm{wt} \%$ composite paper. The far-field EMI SE was measured by a free space method. Fairly good agreement was obtained between the measured and calculated results. Approximately $10-\mathrm{wt} \% \mathrm{CNT}$ is required to achieve composite paper with 20-dB far-field EMI SE.
\end{abstract}

Keywords: Carbon nanotubes; Flexible composites; Nano composites; Electrical properties

Corresponding author. Tel.: +81-055-988-1141

E-mail address: mimai@m.tt-paper.co.jp 


\section{Introduction}

Technical improvement in the electronics field in recent years has diversified and advanced electromagnetic-wave applications. An example is the rapidly increasing use of wireless telecommunications systems, such as cellular phones and RFID tags. In particular, technology that aims for higher frequency and wider bandwidth for establishing a high-speed communication system is advancing. Against this background, however, concerns about deterioration of the radio wave environment have risen. A deteriorated radio wave environment has adverse effects on electronic equipment, such as false operation due to unnecessary electromagnetic waves and leakage of information in wireless telecommunications.

Due to these circumstances, electromagnetic wave absorption materials as technological countermeasures from the viewpoint of electro-magnetic compatibility have gained attention. Usage of these materials is expected to increase in the future.

One candidate material for this application is carbon nanotubes (CNTs). Since their discovery, CNTs have attracted much attention because of their outstanding properties, such as high aspect ratio, high electric conductivity, and high strength. Many studies have been performed on various industrial applications, e.g., battery electrodes, electronic devices, field emission displays, and atomic force microscopes.

Several studies describe preparing and characterizing CNT reinforced composite materials as electromagnetic interference (EMI) shielding materials. For example, Zanfeng et al. prepared single-walled (SW) CNT/epoxy composites and measured the EMI shield effectiveness (SE) of these materials [1]. Grimes et al. made CNT/polyethylmethacrylate composite thick films and determined the permittivity spectra of these composites [2]. The common characteristic of those composite materials is their higher electric conductivities compared with conventional carbon black/polymer composites due to the high aspect ratio of CNT.

CNT/cellulose composite papers have also been reported. For example, Fugetsu et al. fabricated electrically uniform CNT/cellulose composite papers using a CNT water dispersion and indicated the possibility of applying the papers as EMI shielding material [3]. However, systematic analysis of the electrical properties of these papers is required to elucidate their EMI SE characteristics and to design an EMI shielding material.

We report the mechanical and electrical properties of CNT/cellulose composite materials prepared by a paper making process. We measured the EMI SE characteristics of the composite materials and compared them to theoretical characteristics using an electromagnetic field simulator. 


\section{Fabrication}

To optimize the paper making process for CNT/cellulose composites and the quality of the resultant paper, it is important to improve the interaction between the pulp fibers and paper chemicals used in the process, such as starch, sizing agent (bleeding inhibitor of ink), filler, and pigment [4]. The main interaction between these chemicals is ion binding; whether or not these chemicals bond with the pulp fibers depends on the charge of the pulp suspension. Pulp fibers have negative charges because they generate carboxyl groups during the paper making processes such as cooking or bleaching [5]. When anionic surfactant is used to disperse CNTs, CNT surfaces also have negative charges. Therefore, a cationic fixer can be applied to fix the CNTs to the pulp.

CNTs are known to make strong aggregates due to Van der Waals' force. Therefore, it is important to prevent dispersed CNTs from self-agglomerating before bonding them with cellulose fibers. For this purpose, a cationic fixer is mixed with the cellulose fibers so that it adsorbs on the cellulose surfaces before the CNT water dispersion is added. Polymers have three adsorption states on surfaces: train, tail, and loop (Fig. 1) [6]. The train segments are the parts that contact the surface, and the loop and tail segments diffuse in solvents. When a CNT anionic dispersant is added to the cellulose-fixer mixture, the loops and tails of the fixer adsorb on the CNT surfaces and create cross-linkage between the cellulose fibers and CNTs; the bonding of CNTs to cellulose fibers were facilitated. If the fixer is added after the CNT dispersant is mixed with the cellulose, many CNT agglomerates form in the mixture, resulting in non-uniform paper (data not shown) .

Multi-walled (MW) CNTs were provided by Nanocyl S.A. (Nanocyl 7000). The average diameter of the CNTs was $10 \mathrm{~nm}$, and the average length was $1.5 \mu \mathrm{m}$. CNT dispersion of $1 \%$ was provided by Daido Corporation. An anionic surfactant was used to disperse the CNTs [7].

Bleached hardwood Kraft pulp (50-wt\%) and bleached softwood Kraft pulp (50-wt\%) were dispersed in water and beat using a Tappi standard niagara beater until freeness of 500 $\mathrm{ml}$ was obtained. The freeness of the pulp was measured using a Schopper Riegler freeness tester in accordance with JIS P 8121. Then, a fixer of 2\%-cationized starch (Neotack L-1, from Nihon Shokuhin Kako Co.,Ltd.) water solution was added to the pulp and mixed with the CNT dispersion. Hand-made CNT/cellulose composite material was prepared using $25 \times 25 \mathrm{~cm}$ wire cloth. The additive amount of CNT was changed, and six kind of paper were prepared. Usually, the CNT content of a composite is measured using thermogravimetric analysis (TGA) [3]. However, this method could not be applied to our composite paper because the TG curves of the CNTs and cellulose could not be 
distinguished with high accuracy when the components were mixed. Thus, CNT content was calculated by dividing the added amount of CNTs by the sum of the weight of the CNTs and cellulose.

As control materials, carbon black (Mitsui Chemicals \#41) and carbon fiber (Kureha C-103T) were used instead of CNT to produce composite papers. Plain paper was also prepared in the same way.

The CNT/cellulose composite material was coated in gold and observed with a JEOL JSM-6360LA scanning electron microscope (SEM). SEM images of the material are shown in Fig. 2. As shown, CNT networks were observed on the cellulose fibers.

\section{Measurements}

To control the humidity of the paper, the CNT/cellulose composite papers were kept for $24 \mathrm{~h}$ under $23^{\circ} \mathrm{C}, 50 \% \mathrm{RT}$. The tension strength of the papers was measured in accordance with JIS P 8113 using a tensile tester (Kumagaya Riki Kogyo Co. Ltd.). After humidity control, the electrical conductivity was determined by a four-point contact method using a Mitsubishi Chemistry Loresta MCP-HT450 in accordance with JIS K7194.

The scattering (S) parameters for the CNT/cellulose composite papers were measured using a vector network analyzer (VNA) with a bandwidth of $67 \mathrm{GHz}$ (Agilent E8361C) and a K-band (18-26.5 GHz) waveguide. A sample piece of paper was inserted in the waveguide. The permittivity and permeability of the composite papers were extracted from the measured S parameters with material measurement software (Agilent 85071E).

The EMI SEs for the near and far fields were measured using a microstrip line (MSL) and free space methods, as shown in Figs. 3 (a) and 3 (b), respectively. The VNA was used for both methods. An MSL with a characteristic impedance of $50 \Omega$ was fabricated with a FR4 board. The measured frequency range was determined to be from $50 \mathrm{MHz}-25.05 \mathrm{GHz}$ due to the bandwidth of the MSL. The EMI SE was defined by the ratio of transmission when the MSL was not shielded by the sample paper to transmission when the MSL was shielded by a thin insulating sheet and the sample paper. For the free space method, a pair of horn antennas with a bandwidth of 15-40 $\mathrm{GHz}$ was used and the measurement system including the antennas was calibrated with a gated reflection line method.

\section{Results and discussion}

The properties of each composite material are shown in Table 1. The 
CNT/cellulose composites show electric conductivities even when the CNT content is much less than the carbon material content in the other composites. This is attributed to the high aspect ratio of CNTs, which make a network as many conduction paths are effectively formed. It is necessary to optimize the fabrication method for different CNT dispersions. Some methods have been proposed to fabricate CNT/cellulose composite paper, e.g., adjusting the $\mathrm{pH}$ of the suspension solution [3] or mixing a CNT dispersion with cellulose without using any fixer [8]. However, when these methods were applied to this CNT anionic dispersion, the CNT yield was low compared to that when a cationic fixer was used. When 2.5-wt\% CNT was added during the fabrication process, the surface resistivity of the CNT/cellulose composite material using a cationic fixer was $58 \Omega$ /sq., but that when the adjusting-pH method was used was $17,800 \Omega$ /sq. The resistance obtained through the method without fixer was too high to measure by the four-point contact method. Also, adjusting $\mathrm{pH}$ becomes more difficult when the scale of paper making process is larger. Using fixer is thought to be easier way to apply manufacturing machine.

The tensile strengths of the composites are also shown in Table 1. When CNT content was under $5 \%$, the tensile strength of the CNT/cellulose composite was almost the same as that of plain paper. Inter-fiber bonding of cellulose is hydrogen bonding, and adding much carbon or fibers without hydroxyl groups to the pulp inhibits the interaction between cellulose fibers. As shown in Table 1, tensile strength decreased when the added amount of carbon material was increased. However, as described above, CNTs can improve the electric conductivity even when added in small amounts because they form a network structure in the material. Due to this, they interfere with the hydrogen bonding of the cellulose fibers less than other carbon materials do, resulting in highly strong material.

Figure 4 shows the measured conductivity dependence on the CNT content for $\mathrm{CNT} /$ cellulose composite papers along with that for the carbon black (CB)/cellulose and carbon fiber (CF)/cellulose composite papers fabricated for comparison. The effectiveness of the cellulose fiber network as a matrix for increasing the electrical conductivity is compared with CNT composites whose matrices are homogeneous. The figure contains the measured conductivities for CNT composites with insulating matrices reported in the literature [2,9-60, 77]. Our CNT/cellulose composite papers have the highest conductivity reported to date for CNT content of $1-5-w t \%$. The high conductivity of our composite paper is caused by the unique network topology in the paper. A large number of conducting CNT networks is efficiently formed with the help of the cellulose network. This results in high conductivity with only little CNT content. 
In addition, the advantage of CNT over CB and CF was clearly demonstrated.

There are other methods to increase the electrical conductivity for CNT-based materials. One interesting method is to use CNT buckypapers [61]. An extremely large conductance of more than $10^{5} \mathrm{~S} / \mathrm{m}$ was reported for SWCNT buckypaper [62]. In particular, aligning CNTs is effective for increasing the conductivity [63,64]. Although they are useful for electrode applications, CNT buckypapers are unsuitable for EMI shielding. They are metallic and expected to be less effective for near-field EMI shielding as described by Fugetsu et al. [3].

The Cole-Cole plot of permittivity extracted from S parameters measured for CNT/cellulose composite papers is shown in Fig. 5. Both the real and imaginary parts of permittivity ( $\varepsilon_{\mathrm{r}}$ ' and $\varepsilon_{\mathrm{r}}$ ", respectively) increase with increasing CNT content. Scattered data for higher content are caused by the fluctuating frequency dependence of $\varepsilon_{\mathrm{r}}$ ' and $\varepsilon_{\mathrm{r}}$ " as shown in the inset of Fig. 5 . The imaginary part $\varepsilon_{\mathrm{r}}$ ” for all the samples was about half of the value calculated by $\sigma /\left(\omega \varepsilon_{0}\right)$, where $\sigma$ is the measured conductivity, $\omega$ is the angular frequency, and $\varepsilon_{0}$ is the vacuum permittivity. We could not completely determine the reason for this difference. A possible reason might be the accuracy of the software for extracting the permittivity of materials with high conductivities that we used. In fact, the extracted real parts of permeability $\mu_{\mathrm{r}}$ ' for the papers ranged from 0.7 to 1.5. Figure 6 summarizes $\varepsilon_{\mathrm{r}}$ ' as a function of frequency for our composites along with those reported in the literature [24,30,34-36,54,65-75]. Our composite papers are among the highest in the microwave region. The reason for this high $\varepsilon_{\mathrm{r}}$ ' is the same as that for high conductivity. The unique CNT network forms a large number of nanometer-sized capacitors, which results in large polarization and thus large $\varepsilon_{\mathrm{r}}$. The effective permittivities of composites have been evaluated with effective medium theories (EMTs), such as the Maxwell-Garnett formula. Grimes et al. [65] successfully reproduced their experimental permittivity of MWCNT/polystyrene composites with an EMT modified by Lagarkov and Sarychev [76]. We tried to reproduce the measured data with the Lagarkov-Sarychev, Maxwell-Garnett, and Bruggeman formulae but unfortunately did not succeed. A novel formula will be required to describe the permittivity of our composites due to their unique CNT networks.

An example of near-field EMI SE for CNT/cellulose composite papers of $21 \times 21$ cm measured with an MSL method are shown in Fig. 7. The fluctuations observed for CNT/cellulose composite papers with 4.8-wt\% CNT might be due to impedance mismatch between the $50-\Omega$ measurement system and the MSL shielded by the composite paper. A high near-field EMI SE of 50-dB was achieved in the $5-10 \mathrm{GHz}$ frequency region with the $4.8-\mathrm{wt} \% \mathrm{CNT}$ composite paper. We fabricated CNT/cellulose 
composite papers with several levels of CNT content and found the near-field EMI SE had a distinguishing dependence on the sheet resistance of the papers. The near-field EMI SEs at $5 \mathrm{GHz}$ as a function of the sheet resistance are shown in Fig. 8. As can be seen, a sheet resistance of around $40 \Omega$ /sq. was optimum for achieving the maximum EMI SE at $5 \mathrm{GHz}$. Note that the optimum sheet resistance depends on the target frequency. To theoretically confirm the dependence, we performed electromagnetic field simulations using a commercially available finite-difference time-domain simulator. Measured $\varepsilon_{\mathrm{r}}$ ' and conductivity were used in the simulations. The simulation result, shown as a curve in Fig. 8, qualitatively matched the measured data. More than 30-wt\% CF was required to achieve an EMI SE of 30-dB for CF/cellulose composite papers and the EMI SE for CB/cellulose composite paper with 30-wt\% CB was $13 \mathrm{~dB}$. This also demonstrates the advantage of CNT over CB and CF. Metal shielding is less effective for near-field EMI shielding because the metal resistance is too low, as can be seen from Fig. 8.

The far-field EMI SEs measured with the free space method along with theoretical curves are shown in Fig. 9. The theoretical far-field EMI SE was calculated by

$$
\begin{aligned}
& S E=-10 \log _{10}|t|^{2} \\
& t=\frac{\left(1-r_{i}^{2}\right) \exp (-\gamma d)}{1-r_{i}^{2} \exp (-2 \gamma d)},
\end{aligned}
$$

where $r_{i}$ is the reflection at the air and paper interface, $\gamma$ is the propagation constant in the paper, and $d$ is the paper thickness. Measured $\varepsilon_{\mathrm{r}}$ ' and conductivity were used in the calculations. A fairly good agreement was obtained between the measured and calculated EMI SEs. About 10-wt\% CNT was required to achieve 20-dB far-field EMI SE. A metal plate reflects incident waves almost perfectly, but perfect reflection is undesirable for shielding applications such as electronic components.

\section{Conclusion}

We fabricated CNT/cellulose composite materials using a paper making process. Higher electric conductivity and permittivity values compared to those for polymer-based composite materials were achieved without decreasing the paper strength. The EMI SE characteristics measured by the MSL method and the free space method were qualitatively matched to the theoretical characteristics obtained by the simulations. Our CNT/cellulose composite, with its improved EMI SE characteristics, can be used to decrease electromagnetic wave interference, control undesired reflection, prevent cross talk, and suppress noise in circuits. 
References

[1] Zanfeng L, Gang B, Yi H, Yanfeng M, Feng D, Feifei L, Tianying G, Yangsheng C. Reflection and absorption contributions to the electromagnetic interference shielding of single-walled carbon nanotube/polyurethane composites. CARBON 2007; 45: 821-827. [2] Grimes CA, Mungle C, Kouzoudis D, Fang S, Eklund PC. The $500 \mathrm{MHz}$ to 5.50 $\mathrm{GHz}$ complex permittivity spectra of single-wall carbon nanotube-loaded polymer composites. Chem Phys Lett 2000; 319: 460-4.

[3] Fugetsu B, Sano E, Sunada M, Sambongi Y, Shibuya T, Wang X, Hiraki T. Electrical conductivity and electromagnetic interference shielding efficiency of carbon nanotube/cellulose composite paper. Carbon 2008; 46: 1253-1269.

[4] Swanson JW. The science of chemical additives in papermaking. Tappi 1961; 44 (1): 142-181

[5] Kato M, Isogai A, Onobe F. Adsorption behavior of aluminum compounds on pulp fibers at wet-end. Journal of Wood Science 1998; 44(5): 361-368.

[6] Scheutjens JMHM, Fleer GJ. Statistical theory of the adsorption of interacting chain molecules. 2. Train, loop, and tail size distribution. J Phys Chem 1980; 84 (2): 178-190. [7] Morimoto Y, Kubosaki N. Japan Patent Kokai 2007-157440 (21 June, 2007).

[8] Oya T, Ogino T. Production of electrically conductive paper by adding carbon nanotubes. Carbon 2008; 46: 169-171.

[9] Sandler J, Shaffer MSP, Prasse T, Bauhofer W, Schulte K, Windle AH.

Development of a dispersion process for carbon nanotubes in an epoxy matrix and the resulting electrical properties. Polymer 1999; 40: 5967-71.

[10] Kilbride BE, Coleman JN, Fraysse J, Fournet P, Cadek M, Drury A, Hutzler S, Roth S, Blau WJ. Experimental observation of scaling laws for alternating current and direct current conductivity in polymer-carbon nanotube composite thin films. J Appl Phys 2002; 92: 4024-30.

[11] Kymakis E, Alexandou I, Amaratunga GAJ. Single-walled carbon nanotube-polymer composites: electrical, optical and structural investigation. Synth Met 2002; 127: 59-62.

[12] Park C, Ounaies Z, Watson KA, Crooks RE, Smith Jr. J, Lowther SE, Connell JW, Siochi EJ, Harrison JS, St. Clair TL. Dispersion of single wall carbon nanotubes by in situ polymerization under sonication. Chem Phys Lett 2002; 364: 303-8. [13] Allaoui A, Bai S, Cheng HM, Bai JB. Mechanical and electrical properties of a MWNT/epoxy composite. Compos Sci Technol 2002; 62: 1993-8.

[14] Ramasubramaniam R, Chen J, Liu H. Homogeneous carbon nanotube/polymer 
composites for electrical applications. Appl Phys Lett 2003; 83: 2928-30.

[15] Ounaies Z, Park C, Wise KE, Siochi EJ, Harrison JS. Electrical properties of single wall carbon nanotube reinforced polyimide composites. Compos Sci Technol 2003; 63: 1637-46.

[16] Sandler JKW, Kirk JE, Kinloch IA, Shaffer MSP, Windle AH. Ultra-low electrical percolation threshold in carbon-nanotube-epoxy composites. Polymer 2003; 44: 5893-9.

[17] Kim HM, Kim K, Lee CY, Joo J, Cho SJ, Yoon HS, Pejakovic DA, Yoo JW, Epstein AJ. Electrical conductivity and electromagnetic interference shielding of multiwalled carbon nanotube composites containing Fe catalyst. Appl Phys Lett 2004; 84: 589-91.

[18] Martin CA, Sandler JKW, Shaffer MSP, Schwarz MK, Bauhofer W, Schulte K, Windle AH. Formation of percolating networks in multi-wall carbon-nanotube-epoxy composites. Compos Sci Technol 2004; 64: 2309-16.

[19] Grunlan JC, Mehrabi AR, Bannon MV, Barh JL. Water-based single-walled-nanotube-filled polymer composite with an exceptionally low percolation threshold. Adv Mater 2004; 16: 150-3.

[20] Meincke O, Kaempfer D, Weickmann H, Friedrich C, Vathauer M, Warth H. Mechanical properties and electrical conductivity of carbon-nanotube filled polyamide-6 and its blends with acrylonitrile/butadiene/styrene. Polymer 2004; 45: 739-48.

[21] Wang L, Dang ZM. Carbon nanotube composites with high dielectric constant at low percolation threshold. Appl Phys Lett 2005; 87: 042903.

[22] McNally T, Potschke P, Halley P, Murphy M, Martin D, Bell SEJ, Brennan GP, Bein D, Lemoine P, Quinn JP. Polyethylene multiwalled carbon nanotube composites. Polymer 2005; 46: 8222-32.

[23] Aarab H, Baitoul M, Wery J, Almairac R, Lefrant S, Faulques E, Duvail JL, Hamedoun M. Electrical and optical properties of PPV and single-walled carbon nanotubes composite films. Synth Met 2005; 155: 63-7.

[24] Ahmad K, Pan W, Shi SL. Electrical conductivity and dielectric properties of multiwalled carbon nanotube and alumina composites. Appl Phys Lett 2006; 89: 133122.

[25] Dalmas F, Dendievel R, Chazeau L, Cavaille JY, Gauthier C. Carbon nanotube-filled polymer composites. Numerical simulation of electrical conductivity in three-dimensional entangled fibrous networks. Acta Mater 2006; 54: 2923-31. [26] Kymakis E, Amaratunga GAJ. Electrical properties of single-wall carbon 
nanotube-polymer composite films. J Appl Phys 2006; 99: 084302.

[27] Thostenson ET, Chou TW. Processing-structure-multi-functional property relationship in carbon nanotube/epoxy composites. Carbon 2006; 44: 3022-9. [28] Kim HM, Choi MS, Joo J, Cho SJ, Yoon HS. Complexity in charge transport for multiwalled carbon nanotube and poly(methyl methacrylate) composites. Phys Rev B 2006; 74: 054202.

[29] Moisala A, Li Q, Kinloch IA, Windle AH. Thermal and electrical conductivity of single- and multi-walled carbon nanotube-epoxy composites. Compos Sci Technol 2006; 66: 1285-8.

[30] Chang TE, Kisliuk A, Rhodes SM, Brittain WJ, Sokolov AP. Conductivity and mechanical properties of well-dispersed single-wall carbon nanotube/polystyrene composite. Polymer 2006; 47: 7740-6.

[31] Hu G, Zhao C, Zhang S, Yang M, Wang Z. Low percolation thresholds of electrical conductivity and rheology in poly(ethylene terephthalate) through the networks of multi-walled carbon nanotubes. Polymer 2006; 47: 480-8.

[32] Jiang MJ, Dang ZM, Xu HP. Giant dielectric constant and resistance-pressure sensitivity in carbon nanotube/rubber nanocomposites with low percolation threshold. Appl Phys Lett 2007; 90: 042914.

[33] Shi SL, Liang J. Electronic transport properties of multiwall carbon nanotubes/yttria-stabilized zirconia composites. J Appl Phys 2007; 101: 023708. [34] Liu L, Matitsine S, Gan YB, Chen LF, Kong LB, Rozanov KN. Frequency dependence of effective permittivity of carbon nanotube composites. J Appl Phys 2007; 101: 094106.

[35] Huang Y, Li N, Ma Y, Du F, Li F, He X, Lin X, Gao H, Chen Y. The influence of single-walled carbon nanotube structure on the electromagnetic interference shielding efficiency of its epoxy composites. Carbon 2007; 45: 1614-21.

[36] Xiang C, Pan Y, Guo J. Electromagnetic interference shielding effectiveness of multiwalled carbon nanotube reinforced fused silica composites. Ceram Int 2007; 33: 1293-7.

[37] Broza G, Piszczek K, Schulte K, Sterzynski T. Nanocomposites of poly(vinyl chloride) with carbon nanotubes (CNT). Compos Sci Technol 2007; 67: 890-4. [38] Kovacs JZ, Velagala BS, Schulte K, Bauhofer W. Two percolation thresholds in carbon nanotube epoxy composites. Compos Sci Technol 2007; 67: 922-8.

[39] Ma PC, Kim JK, Tang BZ. Effects of silane functionalization on the properties of carbon nanotube/epoxy nanocomposites. Compos Sci Technol 2007; 67: 2965-72. [40] Zhang CS, Ni QQ, Fu SY, Kurashiki K. Electromagnetic interference shielding 
effect of nanocomposites with carbon nanotube and shape memory polymer. Compos Sci Technol 2007; 67: 2973-80.

[41] Lisunova MO, Mamunya YP, Lebovka NI, Melezhyk AV. Percolation behaviour of ultrahigh molecular weight polyethylene/multi-walled carbon nanotubes composites.

Eur Polym J 2007; 43: 949-58.

[42] So HH, Cho JW, Sahoo NG. Effect of carbon nanotubes on mechanical and electrical properties of polyimide/carbon nanotubes nanocomposites. Eur Polym J 2007; 43: 3750-6.

[43] Jiang MJ, Dang ZM, Xu HP. Enhanced electrical conductivity in chemically modified carbon nanotube/methylvinyl silicone rubber nanocomposite. Eur Polym J 2007; 43: 4924-30.

[44] Francis LF, Grunlan JC, Sun J, Gerberich WW. Conductive coatings and composites from latex-based dispersions. Colloid Surf A: Physicochem Eng Aspects 2007; 311: 48-54.

[45] Dai J, Wang Q, Li W, Wei Z, Xu G. Properties of well aligned SWNT modified poly(methyl methacrylate) nanocomposites. Mater Lett 2007; 61: 27-9.

[46] Musumeci AW, Silva GG, Liu JW, Martens WN, Waclawik ER. Structure and conductivity of multi-walled carbon nanotube/poly(3-hexylthiophene) composite films. Polymer 2007; 48: 1667-78.

[47] Jeon K, Lumata L, Tokumoto T, Steven E, Brooks J, Alamo RG. Low electrical conductivity threshold and crystalline morphology of single-walled carbon nanotubes: high density polyethylene nanocomposites characterized by SEM, Raman spectroscopy and AFM. Polymer 2007; 48: 4751-64.

[48] Kim DO, Lee MH, Lee JH, Lee TW, Kim KJ, Lee YK, Kim T, Choi HR, Koo JC, Nam JD. Transparent flexible conductor of poly(methylmethacrylate) containing highly-dispersed multiwalled carbon nanotube. Org Electron 2008; 9: 1-13.

[49] Show Y, Itabashi H. Electrically conductive material made from CNT and PTFE. Diamond Relat Mater 2008; 17: 602-5.

[50] Wang Q, Dai J, Li W, Wei Z, Jiang J. The effects of CNT alignment on electrical conductivity and mechanical properties of SWNT/epoxy nanocomposites. Compos Sci Technol 2008; 68: 1644-8.

[51] Mamunya Y, Boudenne A, Lebovka N, Ibos L, Candau Y, Lisunova M. Electrical and thermophysical behaviour of PVC-MWCNT nanocomposites. Compos Sci Technol 2008; 68: 1981-8.

[52] Chou WJ, Wang CC, Chen CY. Characteristics of polyimide-based nanocomposites containing plasma-modified multi-walled carbon nanotubes. Compos Sci Technol 2008; 
68: 2208-13.

[53] Wu TM, Chen EC. Preparation and characterization of conductive carbon nanotube-polystyrene nanocomposites using latex technology. Compos Sci Technol 2008; 68: 2254-9.

[54] Li Q, Xue Q, Hao L, Gao X, Zheng Q. Large dielectric constant of the chemically functionalized carbon nanotube/polymer composites. Compos Sci Technol 2008; 68: 2290-6.

[55] Mu M, Walker AM, Torkelson JM, Winey KI. Cellular structures of carbon nanotubes in a polymer matrix improve properties relative to composites with dispersed nanotubes. Polymer 2008; 49: 1332-7.

[56] Grossiord N, Kivit PJJ, Loos J, Meuldijk J, Kyrylyuk AV, van der Schoot P, Koning $\mathrm{CE}$. On the influence of the processing conditions on the performance of electrically conductive carbon nanotube/polymer nanocomposites. Polymer 2008; 49: 2866-72. [57] Li Y, Chen C, Zhang S, Ni Y, Huang J. Electrical conductivity and electromagnetic interference shielding characteristics of multiwalled carbon nanotube filled polyacrylate composite films. Appl Surf Sci 2008; 254: 5766-71.

[58] Valentino O, Sarno M, Rainone NG, Nobile MR, Ciambelli P, Neitzert HC, Simon GP. Influence of the polymer structure and nanotube concentration on the conductivity and rheological properties of polyethylene/CNT composites. Physica E 2008; 40: 2440-5.

[59] Murthy DVB, Subramanian V, Sundaray B, Natarajan TS. Microwave hall mobility studies on polymer-single walled carbon nanotube composite fibers. Appl Phys Lett 2008; 92: 222111.

[60] Bonnet P, Sireude D, Garnier B, Chauvet O. Thermal properties and percolation in carbon nanotube-polymer composites. Appl Phys Lett 2007; 91: 201910.

[61] Liu J, Rinzler AG, Dai H, Hafner JH, Bradley RK, Boul PJ, Lu A, Iverson T, Shelimov K, Huffman CB, Rodriguez-Macias F, Shon YS, Lee TR, Colbert DT, Smalley RE. Fullerene Pipes. Science 1998; 280: 1253-6.

[62] Wu Z, Chen Z, Du X, Logan JM, Sippel J, Nikolou M, Kamaras K, Reynolds JR, Tanner DB, Hebard AF, Rinzler AG. Transparent, conductive carbon nanotube films. Science 2004; 305: 1273-6.

[63] Park JG, Li S, Liang R, Fan X, Zhang C, Wang B. The high current-carrying capacity of various carbon nanotube-based buckypapers. Nanotechnol 2008; 19: 185710.

[64] Wang D, Song P, Liu C, Wu W, Fan S. Highly oriented carbon nanotube papers made of aligned carbon nanotubes. Nanotechnol 2008; 19: 075609. 
[65] Grimes CA, Dickey EC, Mungle C, Ong KG, Qian D. Effect of purification of the electrical conductivity and complex permittivity of multiwall carbon nanotubes. J Appl Phys 2001; 90: 4134-7.

[66] Watts PCP, Ponnampalam DR, Hsu WK, Barnes A, Chambers B. The complex permittivity of multi-walled carbon nanotube-polystyrene composite films in X-band. Chem Phys Lett 2003; 378: 609-14.

[67] Wu J, Kong L. High microwave permittivity of multiwalled carbon nanotube composites. Appl Phys Lett 2004; 84: 4956-8.

[68] Xiang C, Pan Y, Liu X, Sun X, Shi X, Guo J. Microwave attenuation of multiwalled carbon nanotube-fused silica composites. Appl Phys Lett 2005; 87: 123103. [69] Saib A, Bednarz L, Daussin R, Bailly C, Lou X, Thomassin JM, Pagnoulle C, Detrembleur C, Jérôme R, Huynen I. Carbon nanotube composites for broadband microwave absorbing materials. IEEE Trans Microwave Theory Tech 2006; 54: 2745-54.

[70] Zhu H, Lin H, Guo H, Yu L. Microwave absorbing property of Fe-filled carbon nanotubes synthesized by a practical route. Mater Sci Eng B 2007; 138: 101-4.

[71] Konyushenko EN, Kazantseva NE, Stejskal J, Trchova M, Kovarova J, Sapurina I, Tomishko MM, Demicheva OV, Prokes J. Ferromagnetic behaviour of polyaniline-coated multi-wall carbon nanotubes containing nickel nanoparticles. J Mag Mag Mater 2008; 320: 231-40.

[72] Shi SL, Liang J. The effect of multi-wall carbon nanotubes on electromagnetic interference shielding of ceramic composites. Nanotechnol 2008; 19: 255707.

[73] Thomassin JM, Pagnoulle C, Bednarz L, Huynen I, Jerome R, Detrembleur C. Foams of polycaprolactone/MWNT nanocomposites for efficient EMI reduction. J Mater Chem 2008; 18: 792-6.

[74] Liu L, Kong LB, Matitsine S. Tunable effective permittivity of carbon nanotube composites. Appl Phys Lett 2008; 93: 113106.

[75] Zhao X, Koos AA, Chu BTT, Johnston C, Grobert N, Grant PS. Spray deposited fluoropolymer/multi-walled carbon nanotube composite films with high dielectric permittivity at low percolation threshold. Carbon 2009; 47: 561-9.

[76] Lagarkov AN, Sarychev AK. Electromagnetic properties of composites containing elongated conducting inclusions. Phys Rev B 1996; 53: 6318-36.

[77]Rosca ID, Hoa SV. Highly conductive mutiwall carbon nanotube and epoxi composites produced by three-roll milling. Carbon 2009; 47: 1958-1968. 


\section{Figure captions}

Fig. 1 Adsorb states of polymers on solid surfaces in water dispersions.

Fig. 2 SEM images of CNT/cellulose composite materials and plain paper.

Fig. 3 Pattern diagrams of (a) MSL method and (b) free space method.

Fig. 4 Measured conductivity dependence on CNT content for CNT/cellulose, $\mathrm{CB} /$ cellulose, and CF/cellulose composite papers and CNT composites with insulating matrices reported in the literature.

Fig. 5 Cole-Cole plot of permittivity extracted from measured $\mathrm{S}$ parameters for CNT/cellulose composite papers.

Fig. $6 \varepsilon_{\mathrm{r}}$ ' of CNT/cellulose composite papers as function of frequency, and those reported in the literature.

Fig. 7 Example of near-field EMI SE for CNT/cellulose composite papers measured with MSL method.

Fig. 8 Near-field EMI SEs at $5 \mathrm{GHz}$ as function of sheet resistance.

Fig. 9 Far-field EMI SEs measured with free space method and their theoretical curves. 
Table 1 Properties of composite materials

\begin{tabular}{|c|c|c|c|c|c|c|}
\hline \multirow{3}{*}{ Material } & $\begin{array}{c}\text { Content } \\
\mathrm{wt} \%\end{array}$ & $\begin{array}{c}\text { Basis weight } \\
\mathrm{g} / \mathrm{m}^{2}\end{array}$ & $\begin{array}{c}\text { Thickness } \\
\mathrm{mm}\end{array}$ & $\begin{array}{c}\text { Surface resistivity } \\
\Omega / \mathrm{sq} .\end{array}$ & $\begin{array}{c}\text { Volume resistivity } \\
\Omega \cdot \mathrm{cm}\end{array}$ & $\begin{array}{c}\text { Tensile strength } \\
\mathrm{N} / \mathrm{m}\end{array}$ \\
\hline \multirow{4}{*}{ CNT } & 0.5 & 110 & 0.166 & $3.39 \times 10^{5}$ & $2.00 \times 10^{3}$ & 6.21 \\
\cline { 2 - 7 } & 1.0 & 116 & 0.186 & $4.51 \times 10^{2}$ & 7.25 & 6.33 \\
\cline { 2 - 7 } & 2.4 & 118 & 0.192 & $5.81 \times 10$ & 1.11 & 6.50 \\
\cline { 2 - 7 } & 4.8 & 122 & 0.191 & $2.89 \times 10$ & $5.21 \times 10^{-1}$ & 6.40 \\
\cline { 2 - 7 } & 9.1 & 117 & 0.195 & $1.29 \times 10$ & $2.66 \times 10^{-1}$ & 4.60 \\
\cline { 2 - 7 } & 16.7 & 126 & 0.166 & 9.12 & $1.49 \times 10^{-1}$ & 4.36 \\
\hline \multirow{5}{*}{ Carbon black } & 9.1 & 115 & 0.212 & $7.51 \times 10^{3}$ & $1.01 \times 10$ & 4.37 \\
\cline { 2 - 7 } & 16.7 & 122 & 0.224 & $7.74 \times 10^{2}$ & 3.83 & 2.96 \\
\cline { 2 - 7 } & 23.0 & 134 & 0.268 & $4.21 \times 10^{2}$ & $4.37 \times 10^{-1}$ & 2.03 \\
\hline Carbon fiber & 10.0 & 116 & 0.222 & $3.39 \times 10^{11}$ & $6.81 \times 10^{11}$ & 6.29 \\
\cline { 2 - 7 } & 30.0 & 106 & 0.265 & $4.61 \times 10^{2}$ & $4.73 \times 10$ & 3.20 \\
\cline { 2 - 7 } & 80.0 & 102 & 0.529 & $1.61 \times 10$ & $2.14 \times 10^{-1}$ & 1.77 \\
\hline Plain paper & - & 104 & 0.169 & - & - & 6.33 \\
\hline
\end{tabular}




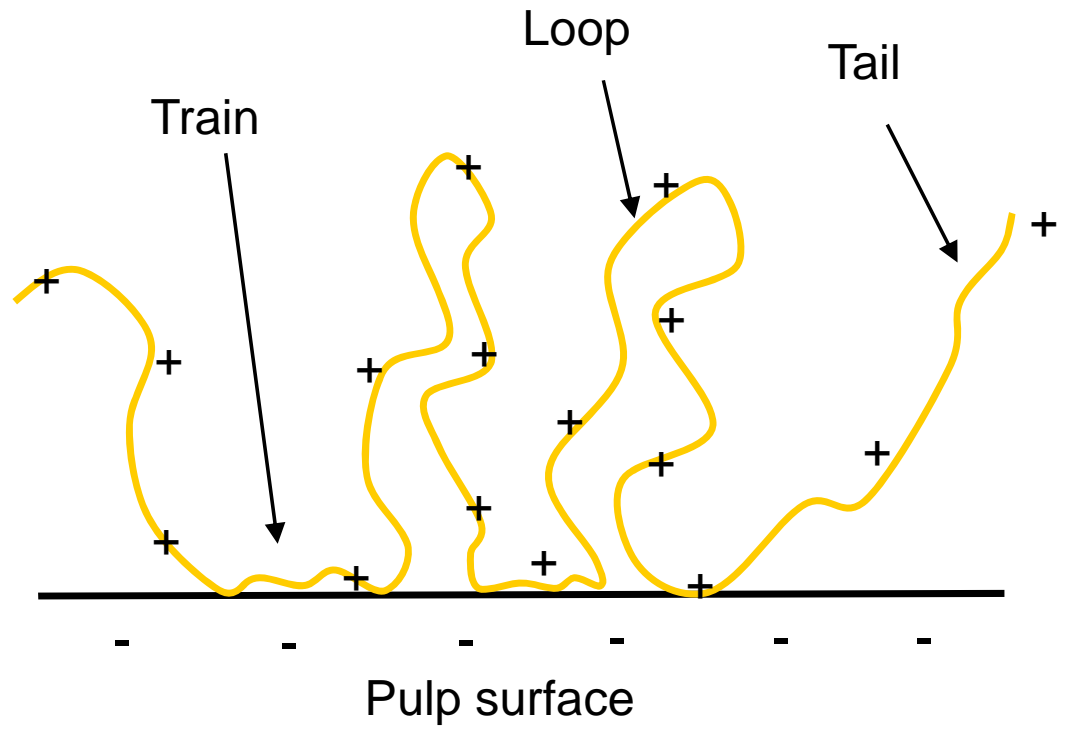

Fig. 1 

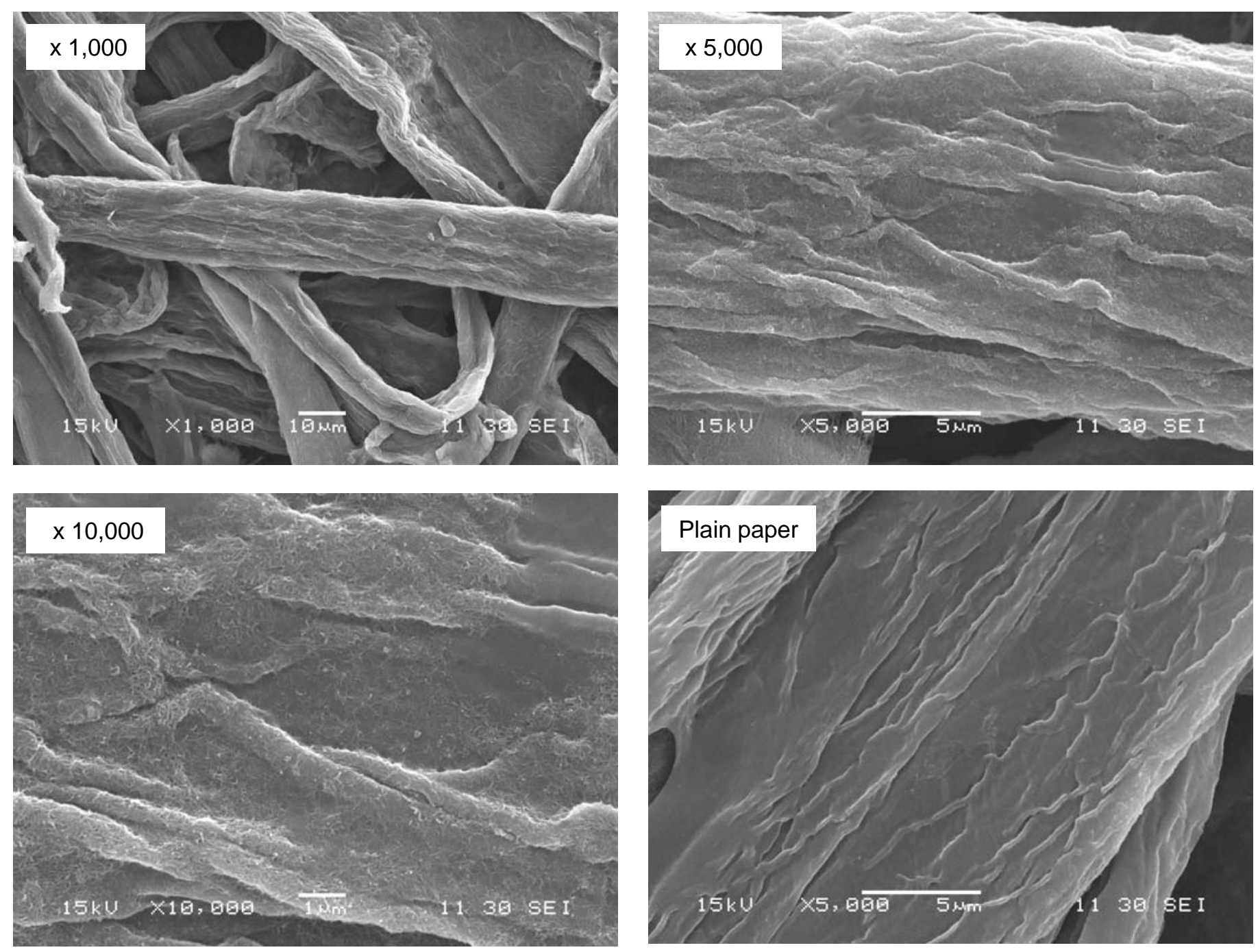

Fig. 2 


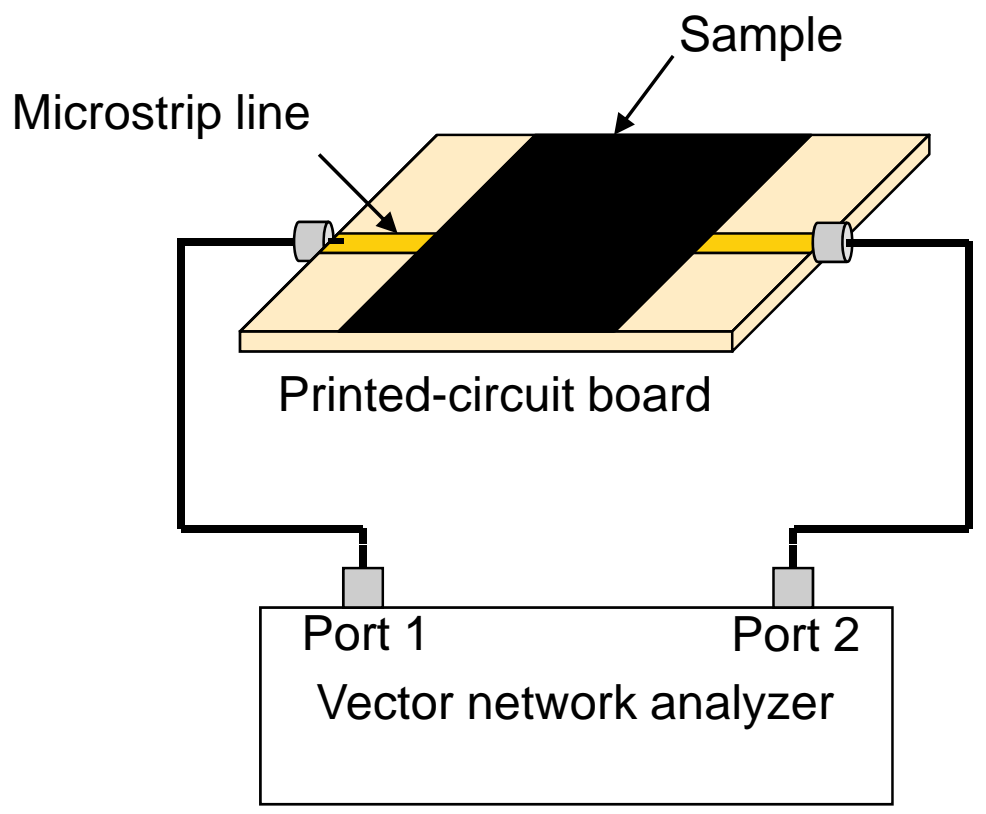

(a)

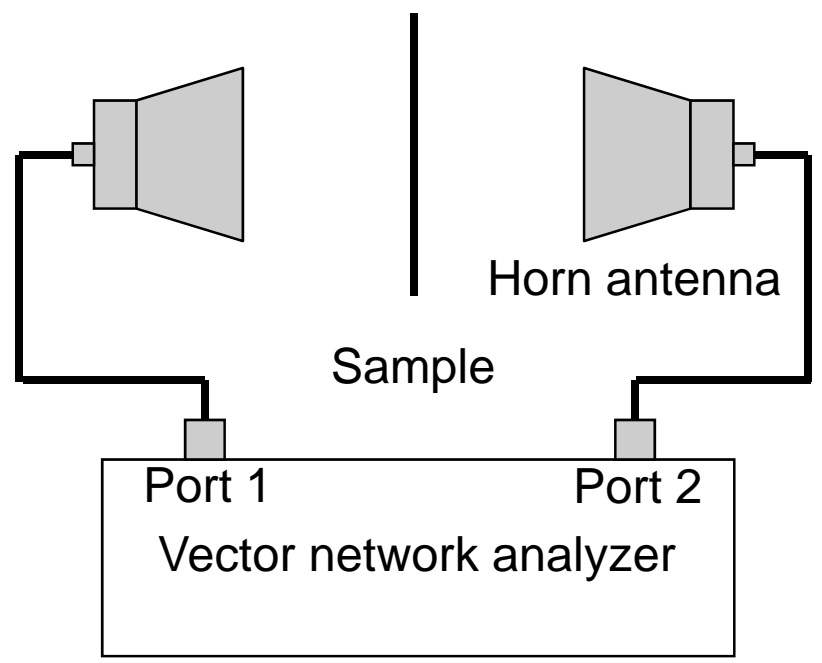

(b)

Fig.3 

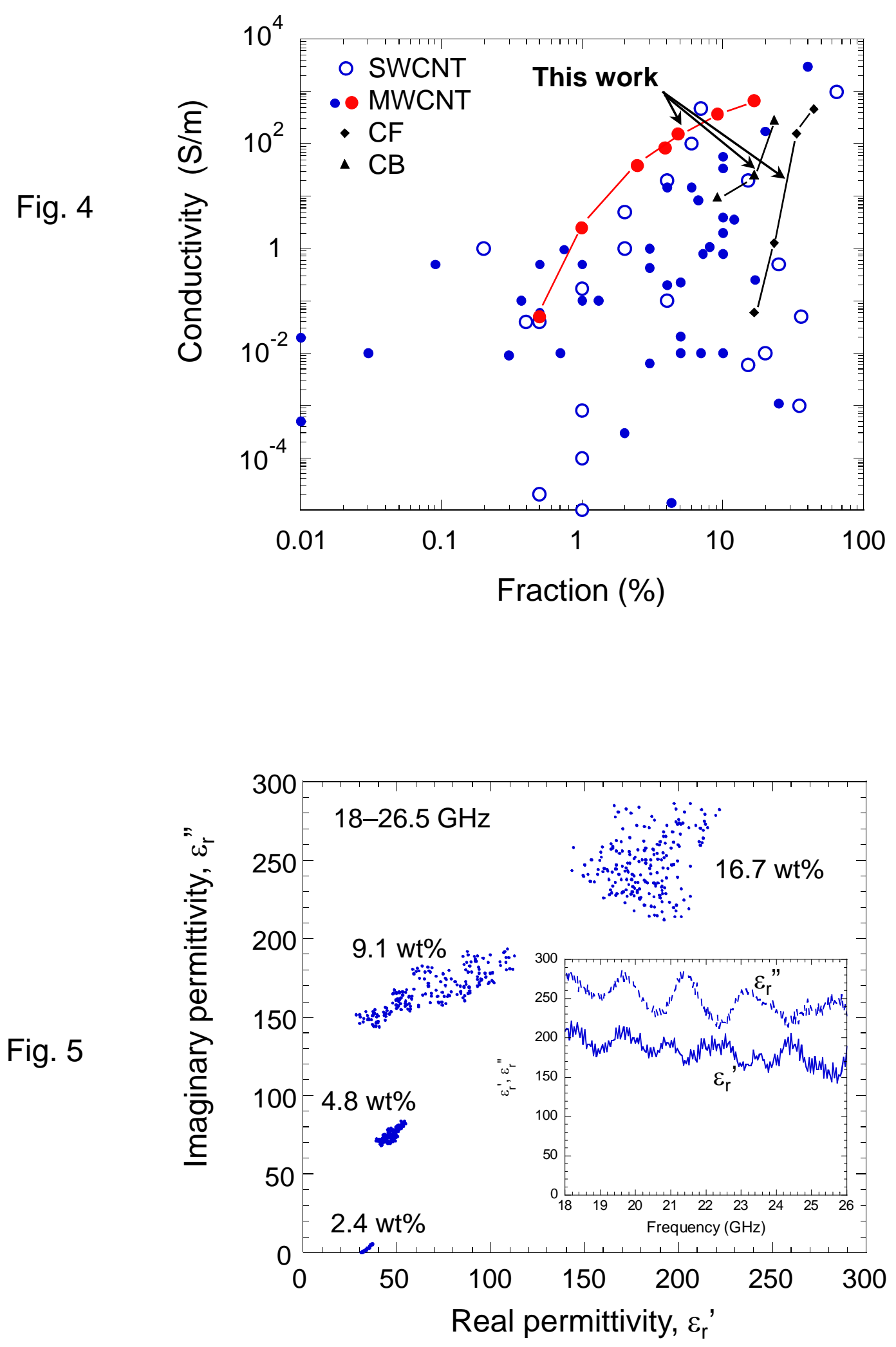

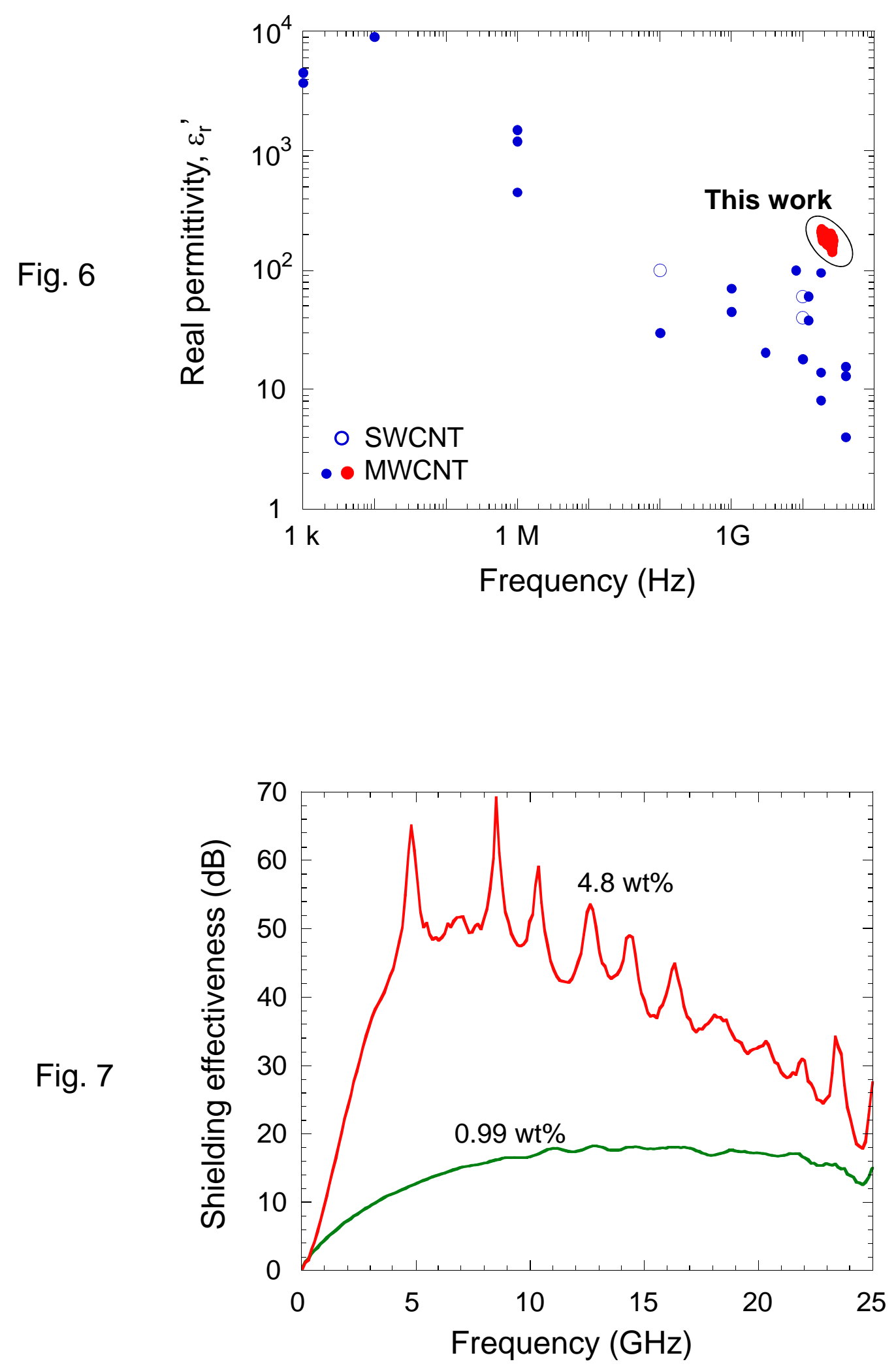
Fig. 8

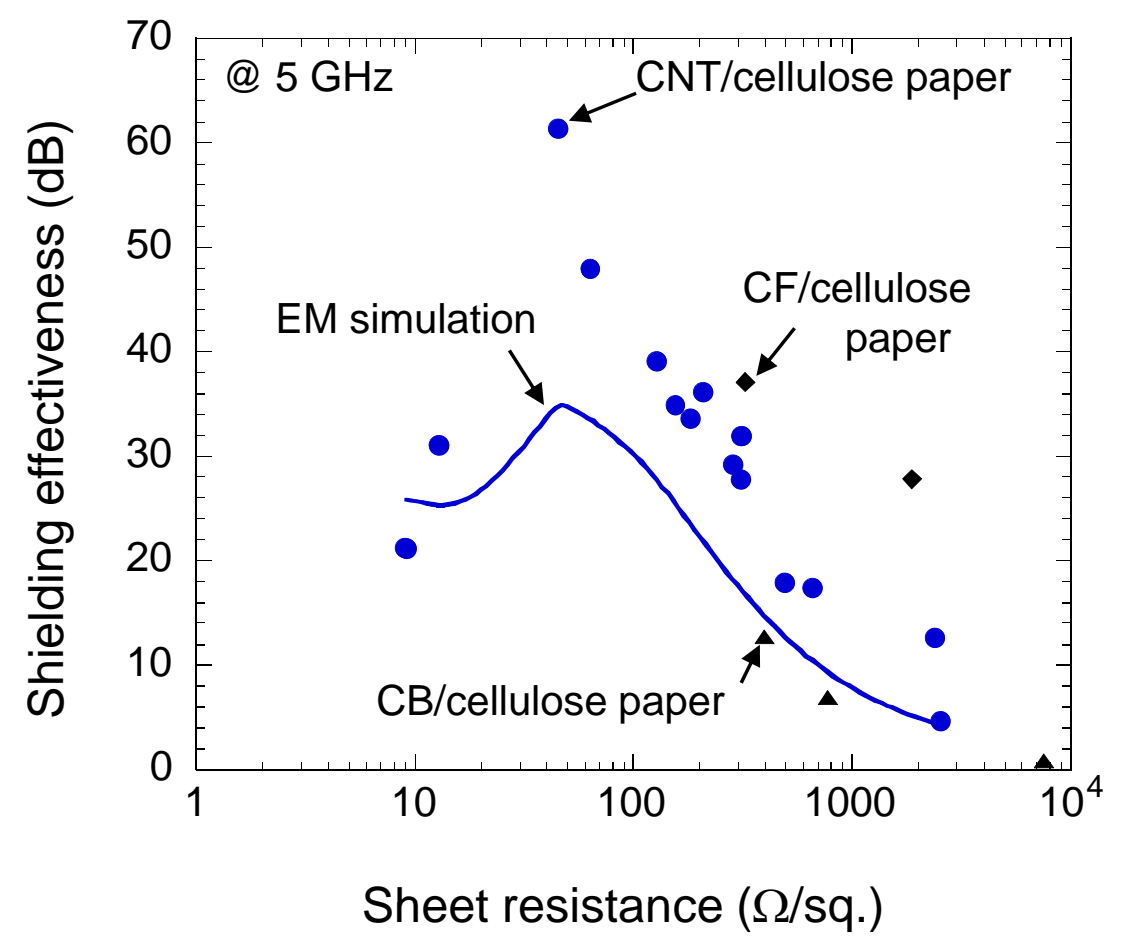

Fig. 9

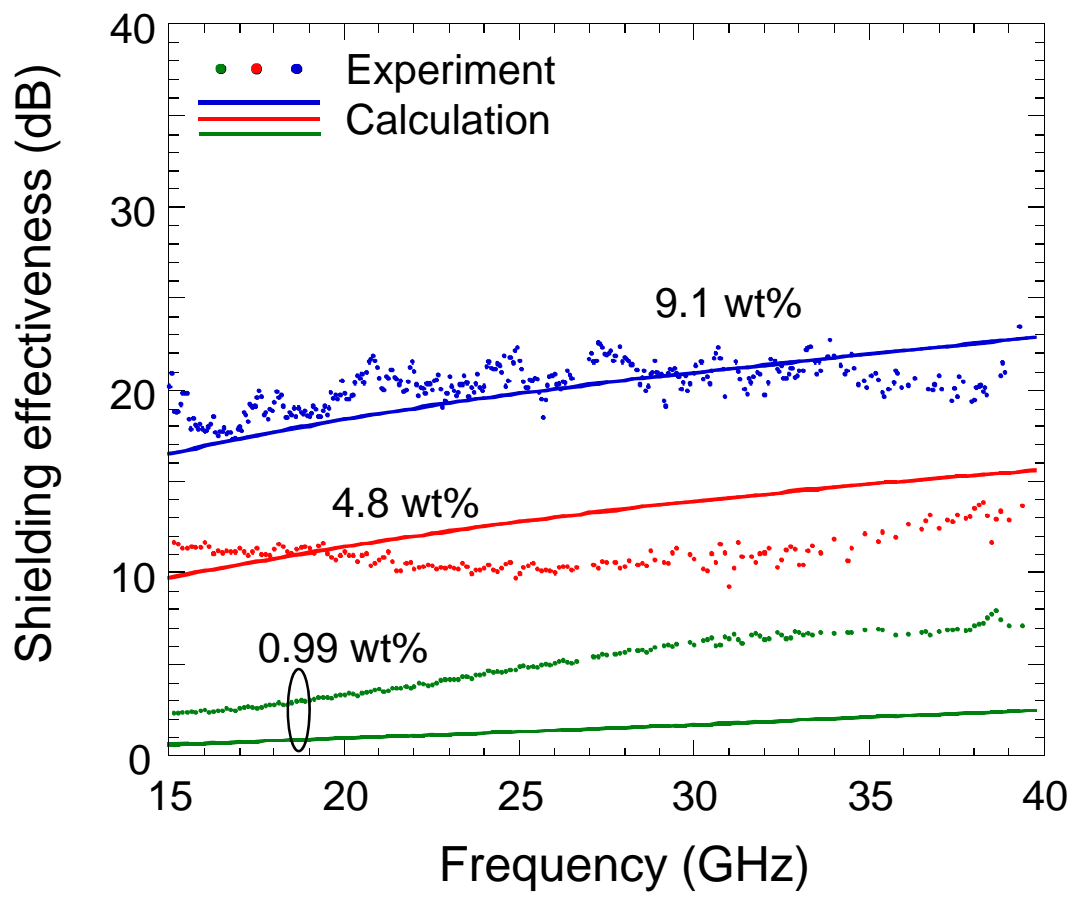

